Version of Record: https://www.sciencedirect.com/science/article/pii/S0016510719316517

Manuscript_51b74ce932dc04ac7a4e6f96be03217d

Journal: Gastrointestinal Endoscopy

Word count: 3322 words

\title{
Title: Pyloric distensibility measurement predicts symptomatic response to intrapyloric botulinum toxin injection
}

Short running title: Pyloric compliance predicts symptomatic response

Authorship:

Desprez Charlotte (1; 2), Melchior Chloé (2; 3), Wuestenberghs Fabien (1; 2), Zalar Alberto (3), Jacques Jérémie (5), Leroi Anne-Marie (1; 4), Gourcerol Guillaume (1; 3; 4).

(1) Rouen University Hospital, Digestive Physiology Unit, Rouen, France

(2) Nutrition, Brain and Gut Laboratory UMR 1073, Rouen University, Rouen, France

(3) Rouen University Hospital, Gastroenterology Department, Rouen, France

(4) Rouen University Hospital, INSERM CIC 1404, Rouen, France

(5) Limoges University Hospital, Gastroenterology Department, Limoges, France

Authorship statement:

All authors approved the final version of the article, including the authorship list.

Guarantor of article: Guillaume Gourcerol

Corresponding author:

Charlotte Desprez

Digestive physiology Unit

Rouen University Hospital - 1 rue de Germont, 76031 Rouen, cedex, France

Phone: + (33) 232888096

Fax: + (33) 235151623

Email address: charlotte-desprez@orange.fr

Specific author contributions: GG, DC performed the research, GG, DC collected and analysed

the data, GG, DC designed the research study and wrote the paper, and DC, GG, MC, WF, ZA, JJ, LAM contributed to editing the manuscript. 
Acknowledgements: The authors are grateful to Nikki Sabourin-Gibbs, Rouen University Hospital, for editing the manuscript.

Conflicts of interest:

Guillaume Gourcerol received consulting fees from Allergan. The other authors have no conflict of interest to declare. 


\section{$\underline{\text { Revised manuscript Version } 2 \text { GIE-D-18-01886 }}$}

\section{Manuscript text: (2717 words)}

\section{Summary: (250 words)}

\section{Background and Aims:}

Recent studies reported that pyloric distensibility was altered in $30 \%$ to $50 \%$ of patients with gastroparesis and this was correlated with gastric emptying and symptom severity.

The aim was to assess whether pyloric distensibility measurement was predictive of symptomatic response after intrapyloric botulinum toxin injection.

\section{Method:}

Pyloric distensibility was measured using EndoFLIP system before intrapyloric botulinum toxin injection. Altered pyloric distensibility was defined as distensibility below $10 \mathrm{~mm} 2 / \mathrm{mmHg}$. Total symptomatic score (TSS), dyspeptic symptoms, Gastrointestinal Quality of Life Index (GIQLI), and gastric emptying were investigated prospectively before and 3 months after botulinum toxin injection.

\section{Results:}

Nineteen of 35 patients had altered pyloric distensibility. In those patients, TSS decreased at 3 months from 13.5 to 10.5 ( $\mathrm{p}<0.01)$, whereas it remained unchanged in patients with normal pyloric distensibility ( $\mathrm{p}=0.7$ ). Gastric fullness (from 3.5 to $2.5 ; \mathrm{p}=0.03$ ) and bloating (from 3.0 to $2.0 ; \mathrm{p}=0.01$ ) were the only symptoms to be improved in patients with altered pyloric distensibility, whereas none of them were improved in patients with normal pyloric distensibility. GIQLI score increased from 59.5 to 76.5 in patients with altered pyloric distensibility $(\mathrm{p}=0.02)$, whereas there was no statistical difference $(\mathrm{p}=0.43)$ in patients with 
normal pyloric distensibility. In patients with altered pyloric distensibility, gastric emptying half time was 223 minutes before and 190 minutes 3 months after injection $(\mathrm{p}=0.02)$, whereas it remained unchanged in patients with normal pyloric distensibility $(\mathrm{p}=0.6)$.

\section{Conclusion:}

Pyloric distensibility measurement before intrapyloric botulinum toxin injection predicted symptomatic and quality of life response 3 months after injection in patients with gastroparesis.

Key words: Gastroparesis, dyspepsia, botulinum toxin, pylorus, distensibility

\section{INTRODUCTION:}

Gastroparesis is defined as objectively delayed gastric emptying in the absence of mechanical obstruction, leading to dyspeptic symptoms ${ }^{1}$. Its prevalence in the United States general population was estimated at 24.2 per 100,000 persons in $2007^{2}$, revealing medical issues in long-term care with an increase in morbidity and mortality in those patients. In the most severe cases, gastroparesis can alter quality of life and nutritional status, with an increasing number of hospitalizations ${ }^{3}$. In addition to idiopathic gastroparesis, which is the most frequent form, the main causes of gastroparesis are diabetes and surgery ${ }^{4}$. Pathophysiology of gastroparesis is complex, with possible contribution of several mechanisms ${ }^{5-6-7}$ leading to gastroduodenal motor abnormalities ${ }^{8}$, including pylorospasm ${ }^{9}$. The study of Mearin et $\mathrm{al}^{10}$ is the first one to our knowledge, to have assessed the implication of impaired pyloric contraction in gastroparesic patients. It revealed that the occurrence and duration of pylorospasm were increased in patients with diabetic gastroparesis compared with healthy controls. A previous prospective study using EndoFLIP system to assess pyloric 
characteristics showed that fasting pyloric distensibility could be altered in a subgroup of 10 out of 26 patients with gastroparesis ${ }^{10}$. Moreover, there was an association in this study between altered pyloric distensibility and delayed gastric emptying. Altered pyloric distensibility was also correlated with more severe dyspeptic symptoms and altered quality of life. In contrast, there was no association with pyloric pressure. These results were confirmed in other populations of patients with gastroparesis or dyspepsia ${ }^{11-12}$.

Botulinum toxin (BT) is a protein natively produced by the bacterium Clostridium botulinum, which blocks neuromuscular conduction. The first case of intrapyloric injection of BT was reported in $1998^{13}$. The positive findings of open-label case series ${ }^{14}$ and a retrospective review ${ }^{15}$ were not confirmed in the two randomized placebo-controlled trials ${ }^{16-}$ ${ }^{17}$. A retrospective analysis identified the existence of a potentially definable subgroup of patients for whom intrapyloric BT injection might be beneficial ${ }^{18}$. However, there is a lack of direct measurement of pyloric motility to identify the best candidates for such treatment in randomized controlled-placebo studies. Therefore, we hypothesized that altered fasting pyloric compliance could predict positive response to intrapyloric BT injection among patients with gastroparesis.

The objective of this study was to assess whether pyloric distensibility measurement was predictive of symptomatic response after intrapyloric botulinum toxin injection.

\section{MATERIAL AND METHODS:}

\section{Approval:}

The study received the agreement of the local ethical review board (Comité d'Ethique de la Recherche Non-Interventionnelle, CERNI, No E2018-68). All patients had given written informed consent before the investigation. 


\section{Patients:}

Patients with diagnosis of gastroparesis refractory to medical therapy (involving resistance to all prokinetics at maximal posology available in France like oral metoclopramide $40 \mathrm{mg}$ per day, oral domperidone $40 \mathrm{mg}$ per day, and oral erythromycin $750 \mathrm{mg}$ per day ${ }^{1}$ ) were consecutively included in the study. Organic gastrointestinal obstruction was ruled out using routine biological blood tests and upper gastro-intestinal endoscopy with biopsies. Patients who had previous endoscopic treatment for gastroparesis were excluded from the study. Improvement at 3 months on symptom scores, quality of life, and gastric emptying were used as evaluation of treatment.

\section{Clinical evaluation:}

Dyspeptic symptoms (vomiting, nausea, epigastric pain, bloating, fullness, and satiety) were recorded before and at 3 months after intrapyloric botulinum toxin injection using specific symptomatic scales. Each item was graded using a 5-point likert scale from 0 (absent) to 4 (most-severe symptoms). Total symptomatic score (TSS) was defined as the aggregation of individual symptom scores. Quality of life was measured using Gastrointestinal Quality of Life Index (GIQLI) score ranging from 0 (worst quality of life) to 144 (best quality of life) ${ }^{19}$. The GIQLI score is specific for digestive disease and has also been validated in French ${ }^{20}$. All questionnaires were answered prospectively by patients during their hospitalization before intrapyloric BT injection and at 3-month evaluation.

\section{${ }^{13}$ C-Octanoic acid breath-test:}

All patients had gastric emptying measurement before and 3 months after intrapyloric BT injection, and were off prokinetics for at least 1 week. After 12 hours of fasting, ${ }^{13} \mathrm{C}$-octanoic 
breath acid breath test was performed according to a previously published method ${ }^{21} 22$. The breath test started between 8:00 $\mathrm{AM}$ and 9:00 $\mathrm{AM}$ with ingestion of a 250-kcal test meal (19\% protein, $43 \%$ carbohydrate, $38 \%$ fat) consisting of white bread (50 g), butter (17 g), and an egg dosed with $91 \mathrm{mg}$ of ${ }^{13} \mathrm{C}$-octanoic acid (Euriso-Top, Saint Aubin, France). Breath samples were collected immediately before meal ingestion and every 15 minutes after the meal for up to 8 hours. Breath samples were investigated for the presence of ${ }^{13} \mathrm{CO}_{2}$ by isotope-selective non-dispersive infrared spectrometry (IRIS; Wagner/Analysen Technik, Bremen, Germany). The solid half-time rate $\left(\mathrm{T}_{1 / 2}\right)$ for gastric emptying was calculated by linear regression analysis using the IRIS software GE2.DEM.

\section{Pyloric distensibility:}

No chronic intake of medication known to affect gastrointestinal function was noted and patients were investigated off prokinetic agents. Pyloric distensibility was investigated after 12-hour fasting using EndoFLIP probe (Crospon Inc) before intrapyloric botulinum toxin injection. The pyloric measurements were performed with the patient under general anesthesia (propofol). An EndoFLIP catheter (EF-325N; Crospon Ltd, Galway, Ireland) was inserted through the single channel of the endoscope. Visual control of the EndoFLIP catheter through the pylorus and the distinctive shape of the pylorus represented as a narrow segment with decreased cross-sectional area (CSA) were necessary to validate correct positioning. The 8$\mathrm{cm}$ balloon was filled with different volumes $(10,20,30,40$, and $50 \mathrm{~mL})$ and for each set volume, at least 3 recordings were made. Retained values needed stable pyloric pressure and CSA for at least 5 seconds, in order to avoid variations in pylorus volume and/or pressure during peristaltic contractions. Moreover, measurement of antral pressure was realized with the deflated bag before and after intrapyloric probe positioning. In our study, pyloric pressure was expressed relative to antral pressure as previously described ${ }^{10}$. The mean value of 3 
measures of the smallest CSA and the corresponding pressure were taken for compliance analysis for each subject. Distensibility was computed using minimum CSA divided by the pressure at each balloon fill volume. A cut-off of $10 \mathrm{~mm}^{2} / \mathrm{mm} \mathrm{Hg}$ at $40 \mathrm{~mL}$ of inflation for normality of distensibility was determined in a previous study ${ }^{10}$ in healthy subjects. We used this threshold value of $10 \mathrm{~mm}^{2} / \mathrm{mm} \mathrm{Hg}$ to classify patients into 2 groups on the basis of normal $\left(>10 \mathrm{~mm}^{2} / \mathrm{mm} \mathrm{Hg}\right)$ or decreased $\left(<10 \mathrm{~mm}^{2} / \mathrm{mm} \mathrm{Hg}\right)$ pyloric distensibility.

\section{Intrapyloric botulinum toxin injection:}

Immediately after investigation of pyloric distensibility by EndoFLIP, intrapyloric botulinum toxin injection was performed during upper GI endoscopy with the patient under general anesthesia. A 0.5-mm sclerotherapy needle was introduced through the biopsy channel of the endoscope. Two hundred units of botulinum toxin (Dysport; Ipsen/Biotech, France) were diluted into $4 \mathrm{~mL}$ of saline solution and then injected per $1 \mathrm{~mL}$ dose in each quadrant of the pylorus.

\section{Data analysis:}

Intra-individual analysis used Wilcoxon signed ranked test for continuous variable (2-tailed). A $p<0.05$ was considered as statistically significant. Correlation studies used the Spearman test. Results were expressed as the median and the $25^{\text {th }}$ and $75^{\text {th }}$ percentile. Data were analyzed using GraphPad Prism version 5.03 for Windows (GraphPad Software Inc, San Diego, California, USA, www.graphpad.com).

\section{RESULTS:}

\section{Patients:}


Thirty-five patients with gastroparesis (12 men), median age 55.1 years (range 25-80), were included between January 2016 and June 2018. The main etiologies of gastroparesis among patients were diabetes $(11 / 35 ; 31.4 \%)$ and surgery $(6 / 35 ; 17.1 \%)$ with 6 Nissen fundoplications. 51\% (18/35) of patients had idiopathic gastroparesis. Using the threshold of $10 \mathrm{~mm}^{2} / \mathrm{mm} \mathrm{Hg}$ at $40 \mathrm{~mL}$ of inflation, we found that 19 of $35(54.2 \%)$ patients had altered pyloric distensibility whereas 16 of 35 patients had normal pyloric distensibility (Figure 1). Characteristics of patients are summarized in Table 1 and no difference was found between the 2 groups.

\section{Impact of pyloric distensibility on TSS and dyspeptic symptoms at 3-month evaluation:}

Twenty-eight of 35 patients answered questionnaires and were included in statistical analysis (reasons for missing data are summarized in Supplementary Figure 1). In patients with altered pyloric distensibility, TSS decreased at 3 months from 13.5 (range 11.0-16.0) to 10.5 (range 8.5-13.0; $\mathrm{p}<0.01)$, whereas it remained relatively unchanged in patients with normal pyloric distensibility from 12.0 (range 9.0-14.5) to 13.0 (range 8.8-16.0; $\mathrm{p}=0.7$; Figure 2). Regarding dyspeptic symptoms, gastric fullness, and bloating were improved in patients with altered pyloric distensibility, with a decrease in scores respectively from 3.5 (range 2.3-4.0) to 2.5 (range 1.8-3.0; $\mathrm{p}=0.03$ ) and from 3.0 (range 2.0-3.8) to 2.0 (range 1.8-3.0; $\mathrm{p}=0.01$ ). None of the dyspeptic symptoms were improved in patients with normal pyloric distensibility. Results of dyspeptic symptoms are more detailed in Table 2. Moreover, similar results were found when the threshold for pyloric distensibility was set at 8 and $9 \mathrm{~mm}^{2} / \mathrm{mm} \mathrm{Hg}$ (data not shown).

\section{Impact of pyloric distensibility on quality of life at 3-month evaluation:}

Among patients with altered pyloric distensibility, quality of life was improved, with an increase in GIQLI score from 59.5 (range 38.0-82.0) to 76.5 (range 66.5-91.0; $\mathrm{p}=0.03$ ), whereas it remained relatively unchanged in patients with normal pyloric distensibility (from 
75.5 [range 52.0-87.0] to 67.0 [range 48.0-89.5; $\mathrm{p}=0.43$; Figure 3]). Similar results were found when the threshold for pyloric distensibility was set at 8 and $9 \mathrm{~mm}^{2} / \mathrm{mm} \mathrm{Hg}$ (data not shown).

\section{Gastric emptying half-time:}

Twenty-eight of 35 patients had ${ }^{13} \mathrm{C}$-Octanoic acid breath-test and were included in statistical analysis (reasons for missing data are summarized in Supplementary Figure 1). Gastric emptying half-time was decreased from 223 (range 157-282) minutes to 190 (range 151-242) minutes at 3 months after intrapyloric botulinum toxin injection $(\mathrm{p}=0.02)$ in patients with altered pyloric distensibility. In contrast, in patients with normal pyloric distensibility, gastric emptying half-time remained relatively unchanged from 214 (range 193-240) minutes to 210 (range 149-243) minutes at 3 months after injection ( $\mathrm{p}=0.6$; Figure 4). Last, similar results were found when the threshold for pyloric distensibility was set at 8 and $9 \mathrm{~mm}^{2} / \mathrm{mm} \mathrm{Hg}$ (data not shown).

\section{DISCUSSION:}

To our knowledge, the present study is the first to have assessed the efficacy of intrapyloric BT injection in patients with gastroparesis, based on the alteration of fasting pyloric distensibility. In our study, altered fasting pyloric compliance was associated with improvement in symptom scores (TSS, gastric fullness, and bloating) and quality of life, in contrary to gastroparesis associated with normal fasting pyloric compliance. Moreover, only decreased fasting pyloric compliance was associated with a decrease in gastric emptying. This is a first signal based on the pathophysiology of gastroparesis to better select patients for pyloric targeting therapeutics. Further confirmatory studies are needed to verify whether this marker is relevant to predict the outcome of gastroparesis treatment. 
We chose fasting pyloric distensibility to assess the efficacy of BT injection in the present study. It has been shown that pyloric distensibility, but not pyloric pressure, was different between healthy volunteers and gastroparetic patients ${ }^{10-11}$. Moreover, altered pyloric distensibility was also predictive of delayed GE, worse symptoms and quality of life ${ }^{10-11}$, confirming our findings. In addition, even if a second pyloric distensibility measurement after BT injection was not reported in the present study, we found in a previous report that pyloric dilatation in 10 patients with gastroparesis and altered pyloric compliance increased pyloric compliance from 7.4 to $20.1 \mathrm{~mm}^{2} / \mathrm{mm} \mathrm{Hg}^{10}$.

Regarding intrapyloric BT injection, the efficacy of this treatment remains controversial based on the analysis of the 2 randomized controlled-placebo trials available in the literature. Arts et $\mathrm{al}^{17}$ did not find a difference in symptoms improvement after saline solution or botulinum toxin injection, suggesting an important placebo effect by endoscopic therapy. But in this study, the population was heterogeneous with mostly idiopathic gastroparesis and the number of subjects in this study was limited to 23 with insufficient statistical power reported by authors. Similarly, Friedenberg et $\mathrm{al}^{16}$ did not find an improvement in symptom scores and quality of life. These similar findings could be partially explained by the overestimated effect of BT on the basis of open reports, but also by the absence of data on pyloric distensibility. It could be interesting to perform further randomized placebo-controlled studies using the EndoFLIP system to assess pyloric distensibility and consequently confirm the association between altered pyloric distensibility and response to BT injection. One of the limits of BT injection is the necessity of repeating injections every 6 to 9 months according to their efficacy among patients. Therefore, other therapeutic interventions specific to the pylorus have been proposed in recent years, with early results for many of them which are promising ${ }^{25}$. On the basis of our results, it could be interesting to reproduce pyloric measurements to assess the efficiency of these different interventions and if 
possible at a longer time than 3-month evaluation. A French prospective study ${ }^{26}$ evaluated the efficacy of peroral endoscopic pyloromyotomy (G-POEM) with assessment of pylorus characteristics using EndoFLIP. They found a distensibility threshold $<9.2 \mathrm{~mm} / 2 \mathrm{~mm} \mathrm{Hg}$ before the G-POEM to discriminate responders and not responders patients; however, all patients were responders at 3 months in this study.

The convenience and reproducibility of EndoFLIP to assess pyloric dysfunction have been also demonstrated using either the single channel therapeutic endoscope, with catheter easily inserted into the pylorus and adjusted under endoscopic and fluoroscopic control ${ }^{11}$ or transnasal insertion under local anesthesia ${ }^{10}$. We found a mean fasting pyloric distensibility of $10.04 \pm 1.67$ at $40 \mathrm{~mL}$ in our cohort of patients with gastroparesis, with similar findings as previous studies, ${ }^{10} 11$ which were performed with the patients under local or general anaesthesia. Only fasting pyloric compliance can be measured because of technical feasibility and the possibility of adverse events. This fasting measure is the only pyloric compliance measurement available in the literature to our knowledge. Nineteen out of 35 patients had decreased fasting pyloric distensibility in our study, using the cut-off of $10 \mathrm{~mm}^{2} / \mathrm{mm} \mathrm{Hg}$, as previously demonstrated ${ }^{10}$. This cut-off was fixed on the basis of a fasting pyloric distensibility measure in healthy volunteers in this study, using $90 \%$ percentile of results on fasting pyloric distensibility at $40 \mathrm{~mL}$ of inflation. Our results on symptom scores, quality of life and gastric emptying were similar when the threshold was set at 8 and $9 \mathrm{~mm}^{2} / \mathrm{mm} \mathrm{Hg}$ at $40 \mathrm{~mL}$ inflation (data not shown). Moreover, we found a correlation between the results of pyloric distensibility with bag volume set at $40 \mathrm{~mL}$ and at $50 \mathrm{~mL}$ (95\% CI, 0.7407-0.9340; $\mathrm{p}<0.0001)$.

A limitation of our study is the number of missing data (Supplementary Figure 1), with a high number of patients who declined to fill questionnaires (7/35) or who did not have the ${ }^{13} \mathrm{C}$-Octanoic acid breath-test (7/35). It has to be underlined that intrapyloric BT injections 
for refractory gastroparesis are not yet reimbursed and that our hospital accepted financial support in exceptional cases. However, even if a small number of patients were included, a significant difference was shown on both symptomatic response and gastric emptying, revealing efficient statistical power. In addition, in previous randomized controlled placebo studies, the number of patients included was similar ${ }^{17-16}$. The BT injection has local neurolytic effects and its duration of response is probably limited by axonal regeneration of cholinergic neurons. Even if a 3-month evaluation can be considered as premature, there is often a decreased effect of BT after this time. Moreover, in the same randomized controlled trials, the evaluation was performed earlier after only 1 month of follow-up.

We did not use Gastroparesis Cardinal Score Index (GCSI) ${ }^{27}$ in our study because to our knowledge, this score has not yet been validated in French at the time we started the study. In addition, the TSS ${ }^{28-29-10}$ is based on the same items as the GCSI, and only the likert scale and the nausea/vomiting subscale which is composed of nausea, retching, and vomiting differs from TSS. In fact, the literal translation of retching in French is similar to that of nausea. We did not use the Patient Assessment of Upper GastroIntestinal Disorders-Quality of Life (PAGI-QOL) questionnaire ${ }^{30}$. This questionnaire was developed to assess quality of life in upper gastrointestinal disorders, but the number of patients with gastroparesis was low (only 28) with none French patients in this subgroup. Each item in the PAGI-QOL is graduated in a 6-point scale, with difficulty of translation in French between them. On the contrary, the GIQLI score has been validated in French ${ }^{20}$ and uses a 5-point scale for each item, even if less specified for upper gastrointestinal disorders. Last, all questionnaires were answered prospectively by all patients at the time of evaluation.

\section{CONCLUSION:}


In the present study, we have shown that pyloric distensibility measurement before intrapyloric BT injection predicted symptomatic and quality of life response 3 months after intrapyloric BT injection in patients with gastroparesis. Further confirmatory studies are needed to verify whether this marker is relevant to predict outcome of gastroparesis treatment and better select patients for pyloric targeting therapeutics. 


\section{REFERENCES:}

1. Camilleri M, Parkman HP, Shafi MA, et al. Clinical Guideline: Management of Gastroparesis. Am J Gastroenterol 2013;108:18-38.

2. Jung H-K, Choung RS, Locke GR, et al. The incidence, prevalence, and outcomes of patients with gastroparesis in Olmsted County, Minnesota, from 1996 to 2006.

Gastroenterology 2009;136:1225-1233.

3. Bharucha AE. Epidemiology and natural history of gastroparesis. Gastroenterol Clin North Am 2015;44:9-19.

4. Soykan I, Sivri B, Sarosiek I, et al. Demography, clinical characteristics, psychological and abuse profiles, treatment, and long-term follow-up of patients with gastroparesis. Dig Dis Sci 1998;43:2398-2404.

5. Buysschaert M, Donckier J, Dive A, et al. Gastric acid and pancreatic polypeptide responses to sham feeding are impaired in diabetic subjects with autonomic neuropathy. Diabetes 1985;34:1181-1185.

6. Grover M, Farrugia G, Lurken MS, et al. Cellular Changes in Diabetic and Idiopathic Gastroparesis. Gastroenterology 2011;140:1575-1585.e8.

7. Choi KM, Gibbons SJ, Nguyen TV, et al. Heme oxygenase-1 protects interstitial cells of Cajal from oxidative stress and reverses diabetic gastroparesis. Gastroenterology 2008;135:2055-2064, 2064.e1-2.

8. Camilleri M, Brown ML, Malagelada JR. Relationship between impaired gastric emptying and abnormal gastrointestinal motility. Gastroenterology 1986;91:94-99.

9. Mearin F, Camilleri M, Malagelada JR. Pyloric dysfunction in diabetics with recurrent nausea and vomiting. Gastroenterology 1986;90:1919-1925.

10. Gourcerol G, Tissier F, Melchior C, et al. Impaired fasting pyloric compliance in gastroparesis and the therapeutic response to pyloric dilatation. Aliment Pharmacol Ther 
$2015 ; 41: 360-367$.

11. Malik Z, Sankineni A, Parkman HP. Assessing pyloric sphincter pathophysiology using EndoFLIP in patients with gastroparesis. Neurogastroenterol Motil 2015;27:524-531.

12. Snape WJ, Lin MS, Agarwal N, et al. Evaluation of the pylorus with concurrent intraluminal pressure and EndoFLIP in patients with nausea and vomiting. Neurogastroenterol Motil 2016;28:758-764.

13. Anon. Sharma VK, Glassman SB, Howden CW, et al. Pyloric intrasphincteric botulinum toxin (Botox) improved symptoms and gastric emptying in a patient with diabetic gastroparesis (abstr) Am J Gastroenterol. 1998;93:456.

14. Ezzeddine D, Jit R, Katz N, et al. Pyloric injection of botulinum toxin for treatment of diabetic gastroparesis. Gastrointest Endosc 2002;55:920-923.

15. Bromer MQ, Friedenberg F, Miller LS, et al. Endoscopic pyloric injection of botulinum toxin A for the treatment of refractory gastroparesis. Gastrointest Endosc $2005 ; 61: 833-839$.

16. Friedenberg FK, Palit A, Parkman HP, et al. Botulinum toxin A for the treatment of delayed gastric emptying. Am J Gastroenterol 2008;103:416-423.

17. Arts J, Holvoet L, Caenepeel P, et al. Clinical trial: a randomized-controlled crossover study of intrapyloric injection of botulinum toxin in gastroparesis. Aliment Pharmacol Ther 2007;26:1251-1258.

18. Coleski R, Anderson MA, Hasler WL. Factors associated with symptom response to pyloric injection of botulinum toxin in a large series of gastroparesis patients. Dig Dis Sci 2009;54:2634-2642.

19. Eypasch E, Williams JI, Wood-Dauphinee S, et al. Gastrointestinal Quality of Life Index: development, validation and application of a new instrument. Br J Surg 1995;82:216222. 
20. Slim K, Bousquet J, Kwiatkowski F, et al. [First validation of the French version of the Gastrointestinal Quality of Life Index (GIQLI)]. Gastroenterol Clin Biol 1999;23:25-31. 21. Ghoos YF, Maes BD, Geypens BJ, et al. Measurement of gastric emptying rate of solids by means of a carbon-labeled octanoic acid breath test. Gastroenterology 1993;104:1640-1647.

22. Gourcerol G, Benanni Y, Boueyre E, et al. Influence of gastric emptying on gastroesophageal reflux: a combined pH-impedance study. Neurogastroenterol Motil 2013;25:800e634.

23. Rohof WO, Hirsch DP, Kessing BF, et al. Efficacy of treatment for patients with achalasia depends on the distensibility of the esophagogastric junction. Gastroenterology 2012;143:328-335.

24. Pandolfino JE, Ruigh A de, Nicodème F, et al. Distensibility of the esophagogastric junction assessed with the functional lumen imaging probe $\left(\mathrm{FLIP}^{\mathrm{TM}}\right)$ in achalasia patients. Neurogastroenterol Motil 2013;25:496-501.

25. Ahuja NK, Clarke JO. Pyloric Therapies for Gastroparesis. Curr Treat Options Gastroenterol 2017;15:230-240.

26. Jacques J, Pagnon L, Hure F, et al. Peroral endoscopic pyloromyotomy is efficacious and safe for refractory gastroparesis: prospective trial with assessment of pyloric function. Endoscopy 2018.

27. Revicki DA, Rentz AM, Dubois D, et al. Gastroparesis Cardinal Symptom Index (GCSI): development and validation of a patient reported assessment of severity of gastroparesis symptoms. Qual Life Res 2004;13:833-844.

28. Davis BR, Sarosiek I, Bashashati M, et al. The Long-Term Efficacy and Safety of Pyloroplasty Combined with Gastric Electrical Stimulation Therapy in Gastroparesis. J Gastrointest Surg 2017;21:222-227. 
29. Grover I, Kim R, Spree DC, et al. Gastric Electrical Stimulation Is an Option for Patients with Refractory Cyclic Vomiting Syndrome. J Neurogastroenterol Motil 2016;22:643-649.

30. Loge C de la, Trudeau E, Marquis $\mathrm{P}$, et al. Cross-cultural development and validation of a patient self-administered questionnaire to assess quality of life in upper gastrointestinal disorders: the PAGI-QOL. Qual Life Res 2004;13:1751-1762.

\section{FIGURES LEGENDS:}

Figure 1. Representative recording of fasting pyloric distensibility in one patient with altered pyloric distensibility of $6.3 \mathrm{~mm}^{2} / \mathrm{mm} \mathrm{Hg}$ (A) and in one patient with altered pyloric distensibility of $13.4 \mathrm{~mm}^{2} / \mathrm{mm} \mathrm{Hg} \mathrm{(B).} \mathrm{Measurements} \mathrm{were} \mathrm{made} \mathrm{at} 40 \mathrm{~mL}$ of inflation.

Figure 2. Evolution of TSS at 3 months after intrapyloric botulinum toxin injection in patients with altered pyloric distensibility (A) and in patients with normal pyloric distensibility (B). TSS decreased at 3 months after injection in patients with altered pyloric distensibility $(\mathrm{p}<0.01)$ whereas no difference was noticed at 3 months in patients with normal pyloric distensibility.

Figure 3. Evolution of GIQLI at 3 months after intrapyloric botulinum toxin injection in patients with altered pyloric distensibility (A) and in patients with normal pyloric distensibility (B). Results are expressed using boxplot (median represented as a line in the interior of the box, $25^{\text {th }}$ and $75^{\text {th }}$ percentiles represented as the lower and upper endpoints of 
the box). GIQLI score was improved at 3 months in patients with altered pyloric distensibility ( $\mathrm{p}=0.02)$ whereas it remained unchanged in patients with normal pyloric distensibility.

Figure 4. Evolution of solid half-time rate $\left(T_{1 / 2}\right)$ for gastric emptying at 3 months after intrapyloric botulinum toxin injection in patients with altered pyloric distensibility (A) and in patients with normal pyloric distensibility (B). Results are expressed using boxplot (median represented as a line in the interior of the box, $25^{\text {th }}$ and $75^{\text {th }}$ percentiles represented as the lower and upper endpoints of the box). $\mathrm{T}^{1 / 2}$ was decreased in patients with altered pyloric distensibility at 3 months $(\mathrm{p}=0.02)$ whereas no difference was noticed in patients with normal pyloric distensibility. 


\section{TABLES:}

\begin{tabular}{|c|c|c|c|}
\hline & $\begin{array}{l}\text { Altered pyloric } \\
\text { distensibility }\end{array}$ & $\begin{array}{l}\text { Normal pyloric } \\
\text { distensibility }\end{array}$ & $P$ value \\
\hline $\mathrm{N}$ & 19 & 16 & \\
\hline \multicolumn{4}{|l|}{ Sex } \\
\hline Men (n) & 7 & 6 & \\
\hline Women (n) & 12 & 10 & \\
\hline \multicolumn{4}{|l|}{ Etiology of gastroparesis } \\
\hline Diabetic & 7 & 4 & \\
\hline Post-fundoplication & 2 & 4 & \\
\hline Idiopathic & 10 & 8 & \\
\hline BMI (kg.m-2) & 22.9 & 23.1 & 0.72 \\
\hline Age (years) & 56 & 55 & 0.66 \\
\hline $\mathrm{T} 1 / 2$ (min) & $223(157-282)$ & $214(193-240)$ & 0.15 \\
\hline TSS & $13.5(11.0-16.0)$ & $12.0(9.0-14.5)$ & 0.29 \\
\hline GIQLI & $59.5(38.0-82.0)$ & $75.5(52.0-87.0)$ & 0.21 \\
\hline \multicolumn{4}{|l|}{ Dyspeptic symptoms } \\
\hline Epigastric pain & $3.0(2.0-3.0)$ & $2.0(1.0-3.0)$ & 0.22 \\
\hline Gastric fulness & $3.5(2.3-4.0)$ & $3.0(2.0-4.0)$ & 0.22 \\
\hline Bloating & $3.0(2.0-3.8)$ & $2.0(0.8-4.0)$ & 0.42 \\
\hline Early satiety & $2.5(2.0-3.0)$ & $1.5(1.0-3.3)$ & 0.18 \\
\hline Nausea & $2.0(0.0-3.0)$ & $2.0(0.8-3.0)$ & 0.99 \\
\hline Vomiting & $0.0(0.0-3.0)$ & $0.0(0.0-2.0)$ & 0.72 \\
\hline
\end{tabular}

BMI, body mass index; TSS, Total symptomatic score; GIQLI, gastrointestinal quality of life index.

Table 1. Patients characteristics before intrapyloric botulinum toxin injection. 


\begin{tabular}{|c|c|c|c|}
\hline & & $\begin{array}{c}\text { Normal } \\
\text { pyloric } \\
\text { distensibility }\end{array}$ & $\begin{array}{l}\text { Altered pyloric } \\
\text { distensibility }\end{array}$ \\
\hline Vomiting & $\begin{array}{r}\text { Pre-injection } \\
\text { Post-injection } \\
P \text { value }\end{array}$ & $\begin{array}{c}0.0(0.0-2.0) \\
0.0(0.0-1.3) \\
0.63\end{array}$ & $\begin{array}{c}0.0(0.0-3.0) \\
0.0(0.0-0.0) \\
0.055\end{array}$ \\
\hline Nausea & $\begin{array}{r}\text { Pre-injection } \\
\text { Post-injection } \\
P \text { value }\end{array}$ & $\begin{array}{c}2.0(0.8-3.0) \\
2.0(1.0-3.0) \\
0.32\end{array}$ & $\begin{array}{c}2.0(0.0-3.0) \\
1.0(0.8-2.0) \\
0.08\end{array}$ \\
\hline Epigastric pain & $\begin{array}{r}\text { Pre-injection } \\
\text { Post-injection } \\
P \text { value }\end{array}$ & $\begin{array}{c}2.0(1.0-3.0) \\
2.0(0.8-3.3) \\
0.90\end{array}$ & $\begin{array}{c}3.0(2.0-3.0) \\
2.0(2.0-3.0) \\
0.24\end{array}$ \\
\hline Bloating & $\begin{array}{r}\text { Pre-injection } \\
\text { Post-injection } \\
P \text { value }\end{array}$ & $\begin{array}{c}2.0(0.8-4.0) \\
2.0(1.0-3.3) \\
\quad 0.62\end{array}$ & $\begin{array}{c}3.0(2.0-3.8) \\
2.0(1.8-3.0) \\
\quad 0.01 *\end{array}$ \\
\hline Gastric fullness & $\begin{array}{r}\text { Pre-injection } \\
\text { Post-injection } \\
P \text { value }\end{array}$ & $\begin{array}{c}3.0(2.0-4.0) \\
3.0(1.0-3.3) \\
0.60\end{array}$ & $\begin{array}{c}3.5(2.3-4.0) \\
2.5(1.8-3.0) \\
\mathbf{0 . 0 3}^{*}\end{array}$ \\
\hline Satiety & $\begin{array}{r}\text { Pre-injection } \\
\text { Post-injection } \\
P \text { value }\end{array}$ & $\begin{array}{c}1.5(1.0-3.3) \\
2.0(1.8-3.0) \\
0.66\end{array}$ & $\begin{array}{c}2.5(2.0-3.0) \\
2.5(1.0-3.0) \\
0.37\end{array}$ \\
\hline
\end{tabular}

Table 2. Evolution of dyspeptic symptoms at 3 months after intrapyloric botulinum toxin injection in patients with altered pyloric distensibility and in patients with normal pyloric distensibility.

\section{SUPPLEMENTARY INFORMATIONS:}

Figure S1. Flowchart of patients who had intrapyloric botulinum toxin injection.

BT: botulinum toxin. GE: gastric emptying. 


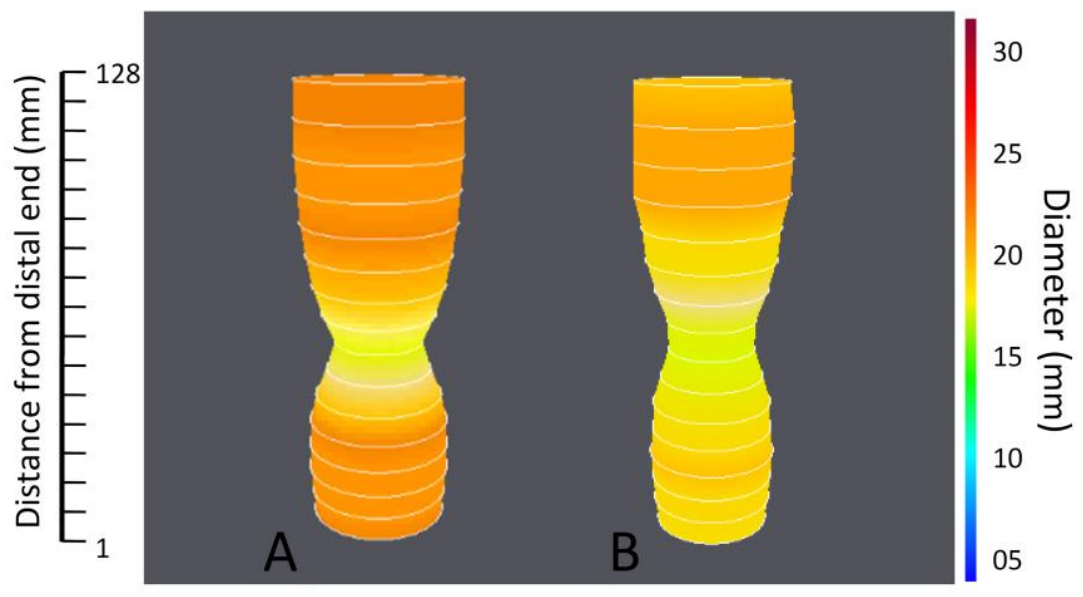




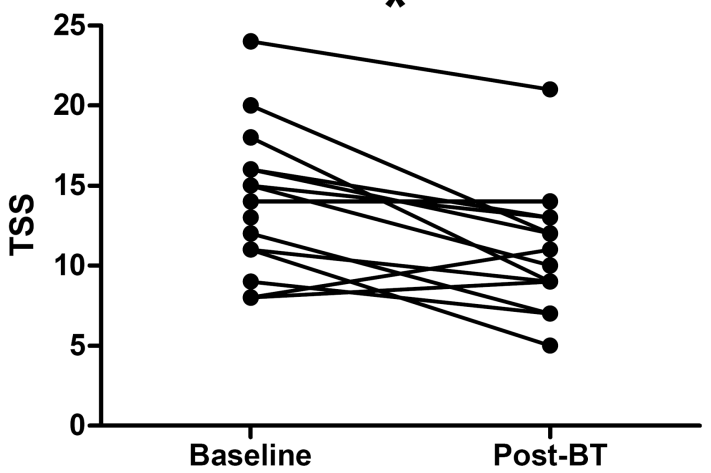




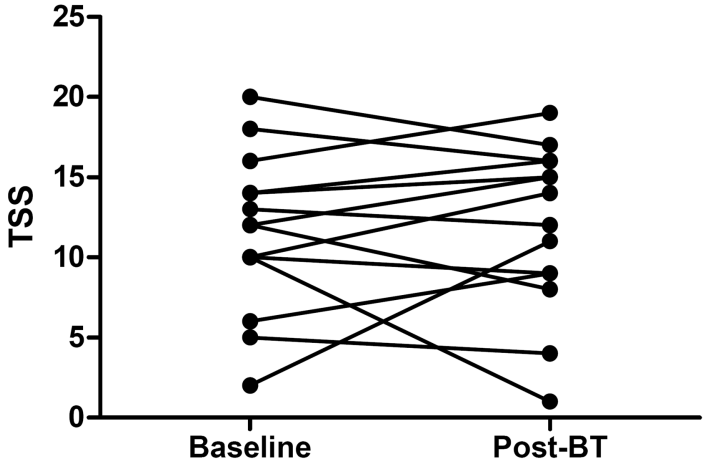




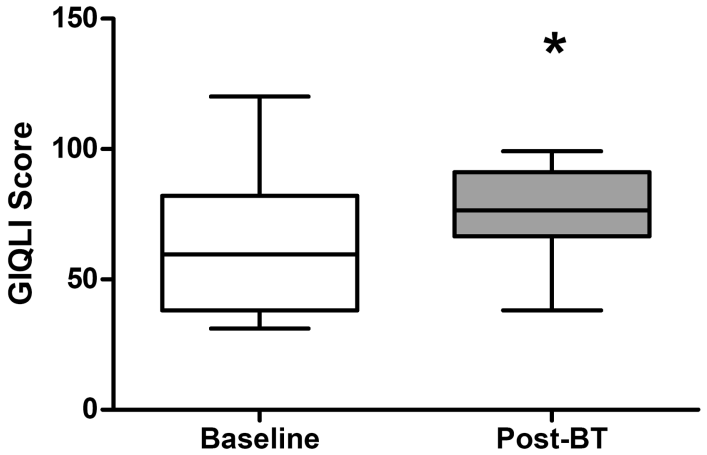




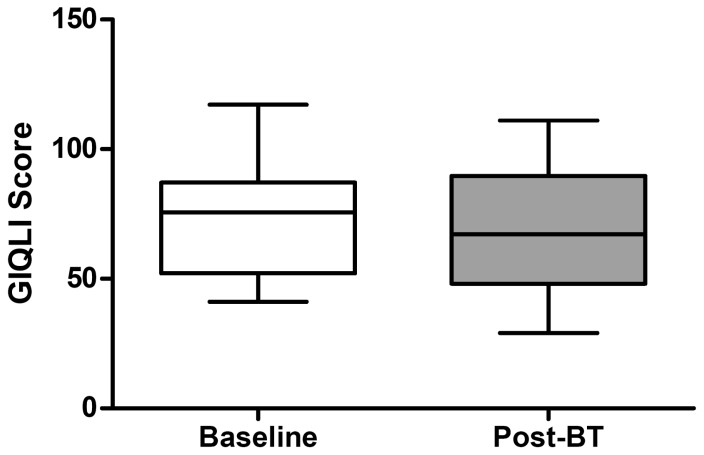




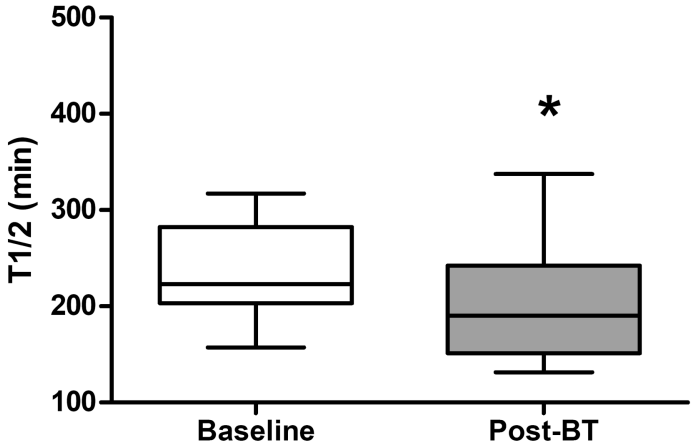




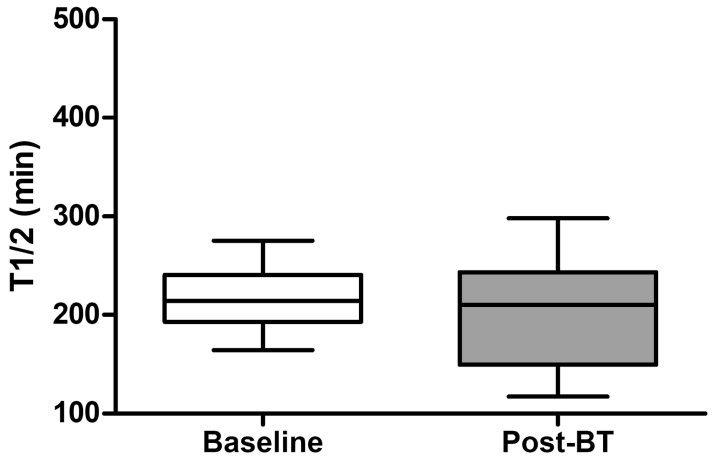




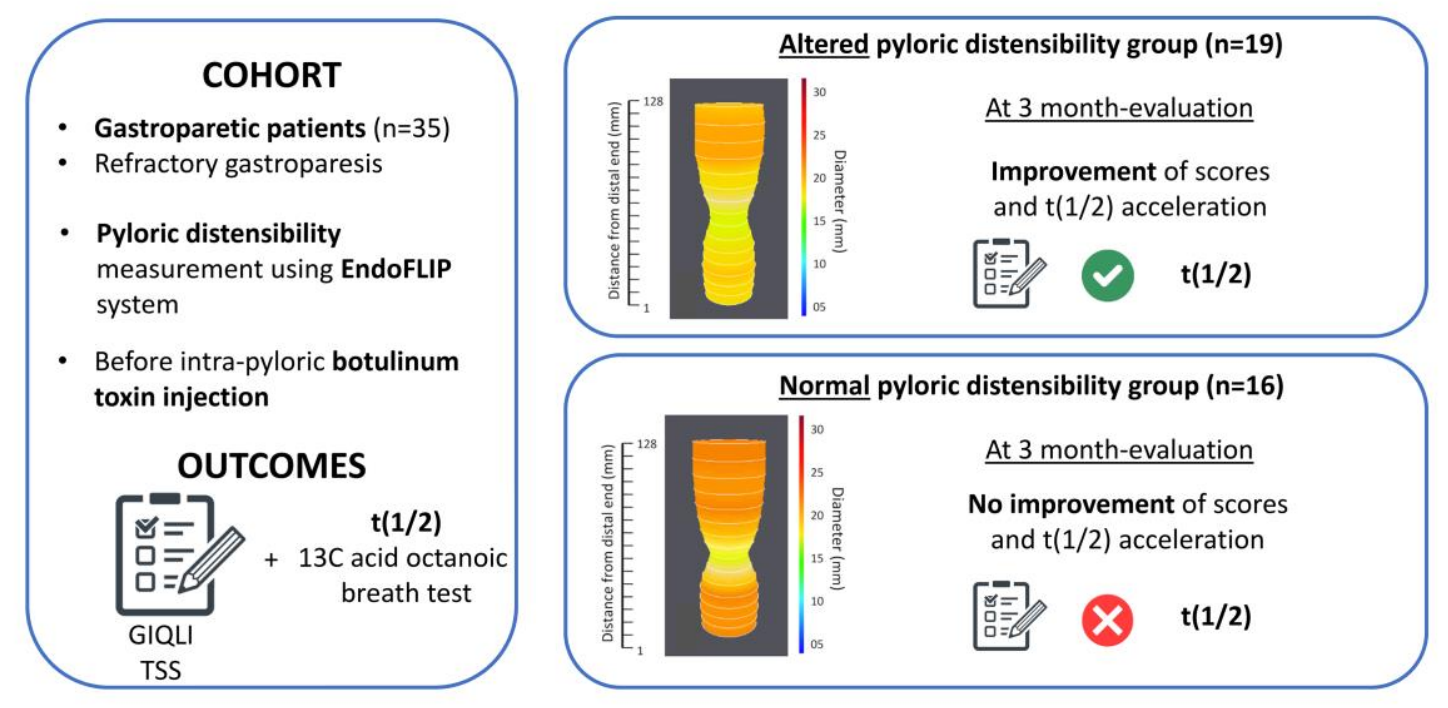

